\title{
Fascination of Sacrifice
}

\author{
Kathryn McClymond
}

We are at a critical juncture in the study of sacrifice. In a world troubled by war, economic crisis, and deprivation, the language of sacrifice is used frequently to rally men and women to extend themselves on behalf of others. Sacrificial rhetoric is used to justify and give meaning and honor to this extra effort, and it is embraced as language rooted in the world's great religious traditions and highest philosophical ideals. At the same time, the resources for scholarship have never been richer in terms of the data and methodologies available. Scholars can draw on ancient texts, archaeological evidence, contemporary philosophy, classical theology, literary works, and popular culture to find examples of sacrifice and to inform their thinking. By contrast, however, theorizing regarding sacrifice in modern Western academia suffers greatly. I would argue that this is largely because sacrificial theorizing continues to be driven by a narrow range of examples and framed largely by Protestant Christian models, in which 1 ) the sacrificial offering substances are assumed to be animal or human; 2) the purpose of the sacrifice is substitutionary atonement via violent destruction; and 3 ) the nature of the sacrifice is monothetic, with a single aspect of sacrifice presented as its defining and essential element. I have argued elsewhere that this approach to sacrifice cripples our appreciation for this rich phenomenon. ${ }^{1}$ We have been seduced by the drama evoked by bloody and violent elements of some forms of sacrifice, and thus distracted from the subtleties and complexities that exist more broadly. As a result, current scholarship is relatively "one note", lacking in sophistication.

The essays in this volume are prompted, at least in part, by a recognition of the current state of sacrificial studies, both its strengths and its weaknesses. The authors represented here take up the rich data and methodological resources available and present a dazzling range of case studies in sacrifice, case studies that lay bare the complex nature of sacrifice. In addition, these essays implicitly challenge the narrow models that dominate sacrificial studies conversations by presenting example after example of sacrifices that cannot be satisfactorily explained by these approaches.

1 An extended presentation of this argument can be found in Kathryn McClymond, Beyond Sacred Violence: A Comparative Study of Sacrifice (Baltimore: Johns Hopkins University Press, 2008). 
Without ever explicitly saying so, this volume also asserts the value of the comparative study of sacrifice. While our work continues to benefit from indepth descriptions and analyses of individual sacrificial systems, the theorizing of sacrifice requires a broad approach, brings multiple sacrificial traditions into conversation with one another. Historically, comparative work has received harsh criticism, largely because early attempts generated ahistorical descriptions of sacrifice that ignored context and glossed over differences between traditions. This reductionist approach led to unwarranted claims about farreaching similarities between traditions. Attempts to address this problem led to an over-correction in which comparison was discounted entirely. Area studies were praised while comparative work was shunned out of fear of overreaching. However, responsible comparison recognizes its limitations, taking on research problems that suit comparison. In addition, responsible comparison is modest in its conclusions. Comparative studies of sacrifice make sense, given the prevalence of sacrifice around the world. In addition, a comparative approach to sacrifice offers a corrective for models that claim universality. The present volume presents a series of case studies of sacrifice, clustered into three sections. Each case study speaks for itself while being framed in conversation with other related essays, giving the reader a sense of the breadth and depth of the issues to be tackled. Ultimately, this approach invites each reader to come to his/her own conclusions about the broader nature of sacrifice.

The study of sacrifice goes back at least as far as the study of religion. In the following few pages, I highlight the prevailing views of sacrifice that this collection implicitly engages. I will briefly describe the approaches that currently dominate the field and then note some of the ways in which these approaches fall short. In so doing, I hope to set the stage for the case studies that follow.

I. While theoretical approaches to sacrifice span a wide spectrum, contemporary theorizing tends to be dominated by three different approaches. Probably the most well-known is that of René Girard, who argues that sacrifice is the unconscious redirected aggression of a society:

[Sacrifice] is a substitute for all the members of the community, offered up by the members themselves. The sacrifice serves to protect the entire community from its own violence; it prompts the entire community to choose victims outside itself. ${ }^{2}$

2 René Girard, Violence and the Sacred, trans. Patrick Gregory (Baltimore: Johns Hopkins University Press, 1977), 8. 
For Girard, scapegoating is at the heart of ritual, religion, even culture as a whole. In his work Girard builds on a Christian notion of vicarious atonement via an innocent victim. He argues: "society is seeking to deflect upon a relatively indifferent victim, a 'sacrificeable' victim, the violence that would otherwise be vented upon its own members, the people it most desires to protect". 3 While it is clear that many sacrificial systems include substitutionary atonement, this motif alone is woefully inadequate as a singular, definitive characterization of all sacrifice.

Others have characterized sacrifice as some form of cuisine. W. Robertson Smith's classic work, Lectures on the Religion of the Semites, focused on sacrifice as a communal meal, in which worshipers reestablish a broken connection with their god, in addition to forging communal ties. ${ }^{4}$ Marcel Détienne and Pierre Vernant, in their work on ancient Greek sacrifice, argue that sacrifice is a kind of political cuisine: "Political power cannot be exercised without sacrificial practice", noting "the political and alimentary vocation inherent in sacrificial practices". 5 Finally, Charles Malamoud, commenting specifically on Vedic sacrifice, argues, "it is essentially a matter of cooking: It is the preparation, sometimes through the combination, but always through the cooking, of edible substances". ${ }^{6}$ While these approaches differ significantly from one another in their understandings of the nature and purpose of the sacrificial meal, they all attempt to argue that the 'meal' or 'cuisine' metaphor captures the thrust of sacrifice.

Finally, scholars have consistently characterized sacrifice as part of a broader system of social exchange. In his classic work The Gift, Marcel Mauss invokes this image, underscoring the fact that no gift is free gift; rather, gift-giving systems depend upon ongoing reciprocity, either between individuals and communities or with the divine: "One of the first groups of beings with which men had to enter into contract, and who, by definition, were there to make a contract with them, were above all the spirits of both the dead and of the gods. Indeed, it is they who are the true owners of the things and possessions of this

3 Girard, Violence and the Sacred, 1.

4 W. Robertson Smith, Lectures on the Religion of the Semites (New York: Meridian Books, 1957 [Orig. 1889]).

5 Marcel Détienne and Pierre Vernant, The Cuisine of Sacrifice among the Greeks, trans. Paula Wissing (Chicago: University of Chicago Press, 1989), 5 .

6 Charles Malamoud, Cooking the World: Ritual and Thought in Ancient India, trans. David Gordon White (New York, Oxford University Press), 34. 
world". ${ }^{7}$ More recently, Gregory Alles has continued imagining sacrifice as a kind of exchange, asserting:

Exchange did provide one of the oldest theoretical models for understanding the widespread ritual of sacrifice: The notion that sacrifices are gifts given to the gods or ancestors in the hope of receiving a gift in return. This perspective is summed up in three Latin words do et des, " I give [to you], to that you will give [to me]".

The phrase do et des is commonplace in sacrificial studies, emphasizing the dynamic that is created between the giver and the recipient in a sacrificial exchange on multiple levels. Again, however, characterizing sacrifice simply as a form of exchange fails to capture other activities and dynamics at play in sacrificial events.

Each of these models offers valuable insights into some sacrificial phenomena, but none of them adequately explores all the sacrificial phenomena available to us, and each of them emphasizes one element of sacrificial practice to the detriment of other elements. We turn now to an explanation of the fundamental problems with these approaches and one possible solution.

II. Common thinking about sacrifice makes several faulty assumptions. First, sacrifice is commonly associated with animal and human victims, but the world's religions include a much wider range of sacrificial offerings. Around the globe we find liquid offerings such as wine and ghee; vegetal offerings such as gourds, grains, and fruit; and material offerings such as fabric. However, theorists have largely ignored or dismissed this fact. Hubert and Mauss acknowledge the existence of vegetal offerings:

It may cause surprise that in this scheme we have not mentioned those cases where the victim is not an animal. We might indeed have done so (...) The preparation of the [grain] cakes, the way in which they were anointed with oil or butter, etc., corresponds to the preparation of the [animal] victim. ${ }^{9}$

7 Marcel Mauss, The Gift: Forms and Functions of Exchange in Arabic Societies, trans. Ian Cunnison (New York: Norton, 1967 [Orig. 1925]), 16.

8 Gregory Alles, "Exchange," in Willi Braun and Russell T. McCutcheon, eds, Guide to the Study of Religion (New York: Cassell, 200o).

9 Henri Hubert and Marcel Mauss, Sacrifice: Its Nature and Functions, trans. W. D. Halls (Chicago: University of Chicago Press, 1964 [Orig. 1898]), 137 n291. 
Vast numbers of sacrificial offerings - and the procedures applied to these offerings - have been largely ignored in sacrificial theorizing to date. I suspect that this is because pouring ghee and pounding grain cakes is not nearly as dramatic as the death of an animal, and the dramatic activities have captured our scholarly attention. However, this narrow focus on animal and human offerings has crippled our understanding.

Related to the focus on the substance of sacrifice is the problem of its purpose. Sacrifice is commonly assumed to be destructive, usually in a violent way. Hubert and Mauss, long viewed as the 'grandfathers' of modern sacrificial studies, state this boldly:

$[\mathrm{W}] \mathrm{e}$ must designate as sacrifice any oblation, even of vegetable matter, whenever the offering or part of it is destroyed. ${ }^{10}$

The procedures that receive attention in sacrificial studies are those that dismember animal victims, and these activities are fundamentally viewed as destructive. However, reviews of the world's sacrificial systems reveal that sacrifice is often a constructive activity. Unique elements are constituted over the course of a sacrifice, and even when a substance is taken apart, this is often best understood as the generation of multiple new, discreet offerings out of a single 'unformed' substance. In addition, the sacrificial ritual itself is often performed in order to stave off destruction, disintegration or chaos. Rather, sacrifices often maintain or reestablish the stability of the cosmos, including the social and political worlds as well as the natural world. In these examples, sacrifice is best understood not as destructive or violent, but as a generative, constructive activity.

Finally, sacrifice has been misrepresented in terms of its nature. Sacrifice is largely characterized as monothetic. That is to say, one element of sacrificial activity - usually consumption or killing - is emphasized as the sole defining element sacrifice. A cursory study of sacrifice, however, reveals that sacrificial events are far more complex. I have argued elsewhere that sacrifice is better understood as a polythetic phenomenon, in which multiple activities combine in countless ways, and none of which is essential or definitive. Sacrificial events include many activities, including the selection of an appropriate sacrificial offering; the association of the offering with a particular deity or deities; the identification of that offering with the sacrificer(s); the killing of some (but not all) offering substances; the apportionment of unformed substances into

10 Hubert and Mauss, Sacrifice, 12. Note that despite this quick reference to vegetal offerings, Hubert and Mauss consciously bracket out vegetal offerings from their theorizing. 
multiple, discrete sacrificial offerings that are distributed to different participants; the heating of offering portions, either by fire or other means; and the consumption of certain portions. Each unique sacrificial event involves combination of these basic "building block" activities, combining in distinctive ways and in specific relationship with one another.

The complexity of sacrificial activity requires us to resist the temptation to reduce sacrifice to a single defining motif - destruction, cuisine, etc. Instead, we are invited to appreciate its multi-faceted, dynamic nature. Sacrifice is an organic phenomenon. It evolves constantly, generating various forms, some of which involve material substances, some of which are internalized processes within the body (e.g., tapas-generating yogic activities), and others of which are metaphoric (e.g., Jewish prayer, reading of the Bhagavad Gita in certain strains of Hinduism). In its different incarnations sacrifice addresses multiple concerns simultaneously: Individual and communal, as well as spiritual, social, economic, political, and cultural. In addition sacrifice manifests itself in multiple realms of human activity: The natural world, the socio-political arena, and countless cultural forms (including visual art, literature, and song). As a result we have an embarrassment of riches upon which to draw, a veritable playground for the scholarly imagination. Our task at this moment in sacrificial scholarship is to reject reductionism and let the full spectrum of sacrificial substances and activities speak to its theorizing.

III. The essays in this volume take up the challenge of reimagining sacrifice with these points in mind. First, they take on sacrifice in relationship with three key constituents: Community, ritual, and identity. In section one, the essays remind us that communities offer the opportunity to offer ourselves in sacrifice - or they demand it. Whatever the dynamic, sacrificial events forge connections between individuals and construct communities as a result. Section two examines sacrificial ritual in a host of religious traditions. We are reminded of the wide range of sacrificial rituals performed in religious and cultural traditions, but more importantly of the variations that occur within specific traditions, depending on time, place, and historical factors. Rituals are sensitive phenomena, and they reflect and respond to their specific contexts. Finally, section three explores the relationship between sacrifice and various identities we craft as individuals. The essays present exercises in the discovery of individual identity, implying that individual identity is always developed in response to other beings and to specific challenges. In clustering the essays in this way the editors underscore the fact that sacrifice never occurs in isolation - it is always constructed, deployed, and negotiated in rich social circumstances. 
The case studies in this volume also display the broad range of data available to scholars of sacrifice. Most obviously, these essays discuss a wide variety of religious sacrificial traditions, including Vedic-Hinduism (Nugteren), early Christianity (Rouwhorst), Catholicism (Poorthuis), Judaism (Lyons, Wallet, Wetter), Islam (Wallet, Ljamai) and that of the Kapsiki/Higi in North Cameroon (Van Beek). In addition, the authors vary widely in the types of data they address. Certain authors draw on historical texts, such as Poorthuis's discussion of Gertrud von le Fort's account of the execution of Carmelite nuns during the French Revolution. Others join in contemporary philosophical and theological debates (Nistelrooy, Wulf). Certain authors draw on creative works. Prevoo examines Friedrich Hölderlin's eighteenth century tragedy Der Tod des Empedocles, while Coenradie explores Harry Potter and the Deathly Hallows and several novels by Shūsako Endō. Two essays focus on modern films: DePoortere addresses Andrei Tarkovsky's 1986 film The Sacrifice. Dresen explores contemporary popular culture in her study of the Twilight vampire saga. Finally, some authors address issues of contemporary concern. Gender is a key issue in Derks's study of the Grail movement, while De Wit explores rhetoric used in justifying self-sacrifice on behalf of one's country. Van Goelst Meijer examines sacrifice in the context of conversations regarding nonviolence.

The breadth of data presented here invites us to reimagine the substance, the nature, and the purpose of sacrifice in its countless manifestations. In so doing, the essays in this volume challenge us to infuse our theorizing about sacrifice with the same richness and complexity we find in sacrifice itself. We will never fully comprehend sacrifice - and in the end, this may be why it continues to fascinate. 